\title{
Chemopreventive Effects of Magnesium Chloride Supplementation on Hormone Independent Prostate Cancer Cells
}

\author{
Saheed Oluwasina Oseni, "Elsa Quiroz, and James Kumi-Diaka
}

Department of Biological Sciences, Florida Atlantic University, Davie, FL 33314, USA

*Corresponding Author: Elsa Quiroz, Department of Biological Sciences, Florida Atlantic University, Davie, FL 33314, USA

Submission Date: November 12, 2015, Acceptance date: January 12, 2016: Publication date: January 14, 2016

\begin{abstract}
Background: Lifestyle significantly impacts the risk factors associated with prostate cancer, out of which diet appears to be the most influential. An emerging chemopreventive approach, which involves the adequate intake of dietary constituents, has shown great potential in preventing the occurrence or progression of cancer. Magnesium is known to be an essential cofactor for more than 300 enzymatic processes, and is responsible for the regulation of various cellular reactions in the body. A plethora of studies have shown evidence that changes in the intracellular levels of magnesium could contribute to cell proliferation and apoptosis in some normal and malignant cells. The aim of the study was to investigate the effects of magnesium chloride $\left(\mathrm{MgCl}_{2}\right)$ in DU145 prostate cancer cells.
\end{abstract}

Methodology: Cultured DU-145 cells were subjected to graded concentrations or doses (50-500 $\mu \mathrm{M})$ of $\mathrm{MgCl}_{2}$ for 48 hours. The cell viability was assessed using MTT and Resazurin reduction assays. NBT assay was also used to assess the treatment-induced intracellular ROS levels. Acridine Orange/Ethidium Bromide (AcrO/EtBr) and Rh123/EtBr fluorescent stains were used to assess the cell death type and mitochondrial membrane potential $(\Delta \psi \mathrm{m})$ respectively.

Results: The results revealed a dose-dependent decrease $(P<0.05)$ in cell viability in treated DU-145 cells after 48 hours. The NBT assay also revealed a dose dependent biphasic response $(P<0.05)$ in intracellular levels of ROS. There was a drop $(P<0.05)$ in ROS levels in all groups except at $100 \mu \mathrm{M}$, where ROS level was higher than the control. Apoptosis was the primary mode of cell death as observed in the fluorescence analysis.

Conclusion: Our finding suggests that $\mathrm{MgCl}_{2}$ may be potentially chemopreventive for prostate cancer. This justifies further studies into its mechanism of action in DU-145 and other prostate cancer cell types. 
Keywords: Prostate cancer, Magnesium chloride, Chemoprevention, Apoptosis, Reactive Oxygen Species.

\section{INTRODUCTION}

Prostate cancer $(\mathrm{PCa})$ is the $2^{\text {nd }}$ leading cause of cancer in U.S. men, and it represents $13.3 \%$ of all cancer cases in the U.S. [1]. In 2015 alone, an estimated 220,800 new cases and 27,540 deaths are expected to occur due to prostate cancer, adding to the burden of the over 2.6 million men currently living with the disease in the country [2]. Lifestyle coupled with aging has been shown to be one of the predisposing factors that may account for about 75 percent of the prostate cancer cases, and of all the environmental variables, diet appears to be the most influential [3]. An emerging chemopreventive approach involving the adequate intake of dietary constituents has shown great potential in preventing the occurrence or progression of cancer [4].

Magnesium is known to be an essential cofactor for more than 300 enzymatic processes responsible for the regulation of various cellular reactions in the body [5]. Magnesium has been shown to be an indispensable element in all of the body's natural self-cleansing and detoxification responses due to its ability to chelate with intracellular ATP and competitively bind with calcium for binding sites on proteins and cell membranes [6]. Without sufficient magnesium, toxic waste and acid residues accumulate in cells and tissues, setting the stage for chronic degenerative conditions, cancer, and rapid aging symptoms [7]. Plethora of studies have shown evidences that change in the intracellular levels of minerals and micronutrients, such as magnesium, could contribute to the modulation or regulation of cell proliferation and apoptosis in some normal and malignant cells [8].

Magnesium occurs naturally in many forms, but is most readily assimilated and utilized for metabolic purposes. The distribution of magnesium in the body is as such; $60 \%$ in bone, $20 \%$ in skeletal muscle, $19 \%$ other soft tissues, and less than $1 \%$ in blood serum [9]. It has been shown that the average diet in the U.S. is deficient in magnesium [10]. This was confirmed through a survey that was performed to determine the daily intake of magnesium in U.S. population, and was found to be $32 \%$ and $20 \%$ less than the daily recommended dietary allowance (RDA) in women and men respectively [11]. This was also found to be similar in most other countries.

Prostate cancer is a slow growing tumor, and has been documented to be strongly correlated with aging, with the highest prevalence indicated in men above 60 years of age, but not below 40 [1]. A link between magnesium and aging has been a topic of discussion in literatures, with insufficient intake of magnesium in diet or variance in magnesium metabolism associated with aging process and susceptibility to age-related diseases [12]. For instance, magnesium imbalance in elderly people was found to be associated with inflammation, cardiovascular diseases, diabetes, and stress vulnerability [7]. However, metabolism in normal and abnormal cells is markedly different, and the links between cancer and magnesium status perhaps may rely on cellular and subcellular backgrounds. The aim of the study was to investigate the chemopreventive effects of magnesium chloride $\left(\mathrm{MgCl}_{2}\right)$ supplementation on DU-145 hormone refractory prostate cancer cells. 


\section{MATERIALS AND METHODS:}

Cell Line and Cell Culture: DU-145 cell line was purchased from ATCC (Manassas, Virginia, USA). It is a hormone independent prostate cancer cell line. The DU-145 cells were cultured and maintained in complete RPMI 1640 (Sigma Aldrich Chemical Co., St Louis, Mo, USA) media with $10 \%$ Fetal Bovine Serum and $1 \%$ penicillin/streptomycin.

Micronutrient: Magnesium Chloride $\left(\mathrm{MgCl}_{2}\right)$ (100\% pure) was purchased from Seychelles Organics, Inc. (Life-Flo, Bowling Green, Florida, USA) and dissolved into a stock solution (1 $\mathrm{mM}$ ) with deionized water. Stock solution of $\mathrm{MgCl}_{2}$ was further diluted with RPMI-media to produce aliquots ranging in concentration from $50-500 \mu \mathrm{M}$.

Treatment: The DU-145 cells were cultured in $25 \mathrm{~cm}^{3}$ flask at $37^{\circ} \mathrm{C}, 5 \% \mathrm{CO}_{2}$ and $89 \%-90 \%$ humidity to achieve $80 \%$ - $90 \%$ confluence. The cells were harvested, centrifuged and reconstituted into suspension with fresh RPMI 1640 media. $1 \times 10^{4}$ cells in $100 \mu \mathrm{L}$ of media were dispensed into each well of 96 well microtiter plates and cultured for 48 hours to allow adherence and to obtain greater than $80 \%$ confluence. The media (supernatants) for each well were aspirated and the adhered cells were treated with graded concentrations of $\mathrm{MgCl}_{2}(50,60$, $70,80,90,100,200,300,400,500 \mu \mathrm{M})$. Experiments had a control group consisting of DU-145 cells cultured in RPMI 1640 media (with $10 \%$ FBS, $1 \%$ penicillin/streptomycin and Lglutamine) without treatment $(0 \mu \mathrm{M})$. All treatments were done in quadruplicates, and cultured for $24-48$ hours in a humidified incubator at $37^{\circ} \mathrm{C}$ and $5 \% \mathrm{CO}_{2}$. At 24 and 48 hours posttreatment/culture, cells were subjected to bioassay analyses as follows:

Trypan Blue Exclusion Assay: Trypan blue exclusion assay was used to assess the cell viability and initial concentration of the DU-145 cells added to the microplate wells prior to treatment, according to standard procedures using a Neubauer counting chamber. The trypan blue exclusion assay allows for a direct identification and enumeration of live (unstained) and dead (blue) cells in a given population. Briefly, the trypan blue stock $(0.4 \%)$ was diluted with PBS to $0.2 \%$ and filtered the trypan blue with 0.2 micron filter. The cell suspension was then mixed with the $0.2 \%$ trypan blue at 1:1 ratio. Counting chamber slide was loaded and analyzed.

MTT Assay: MTT [3-(4, 5-dimethyl thiazolyl-2)-2, 5-diphenyltetrazolium bromide], a tetrazolium dye, is used to determine metabolic status and cell viability. Since the resulting color intensity correlates directly with the amount of metabolically active cells in each well, cell viability can be quantitatively determined by measuring the optical density (OD) in individual wells. After briefly treating the cells as described previously, a volume of $20 \mu \mathrm{L}$ of MTT reagent was added to each well at 48 hours post-treatment. The plates were further incubated at $37^{\circ} \mathrm{C}$ and $5 \% \mathrm{CO}_{2}$ for 4 hours in the dark, after which a volume of $100 \mu \mathrm{L}$ of DMSO was added to the cells to solubilize the formazan. Absorbance (OD) of the resultant solution was read at $490 \mathrm{~nm}$ using a BioTek microplate reader (Winooski, Vermont, USA). The relative population of live cells could therefore be determined based on the optical absorbance (optical density, OD) of the sample. The OD obtained was graphed against the concentrations of the $\mathrm{MgCl}_{2}$. The values of the blank wells 
were subtracted from each well of treated and control cells; and the mean percentage of posttreatment viable cells relative to the controls was calculated as shown:

Cell viability $(\%)=A_{T}-A_{B} / A_{C}-A_{B}$

Where $A_{C}$ is the absorbance of the control (mean value), $A_{T}$ is the absorbance of the treated cells (mean value), and $\mathrm{A}_{\mathrm{B}}$ is the absorbance of the blank (mean value). The $\mathrm{IC}_{50}$ was extrapolated from the graphs as a measure to determine the concentration required to obtain expected results (potency).

Resazurin (Alamar Blue) Reduction Assay: Resazurin (Alamar blue) is a cell permeable redox indicator that can be used to monitor viable cell number with protocols similar to those utilizing the tetrazolium compounds, but slightly more sensitive than tetrazolium reduction assays. Viable DU-145 cells with active metabolism can reduce resazurin into the resorufin product, which is pink and fluorescent. This resorufin can then be quantified by measuring a change in absorbance. Briefly, high purity resazurin was dissolved in DPBS ( $\mathrm{pH} 7.4$ ) to $0.15 \mathrm{mg} / \mathrm{ml}$ to make a stock solution. This was then Filter-sterilized through a $0.2 \mu \mathrm{m}$ filter into a sterile, light protected container and stored from light at $4^{\circ} \mathrm{C}$ for frequent use. $20 \mu \mathrm{L}$ resazurin solution to each well containing $\mathrm{MgCl}_{2}$ treated DU-145 cells (in 96-wells microplate at a final volume of $100 \mu \mathrm{L} /$ well after 48 hours of incubation at $37^{\circ} \mathrm{C}$ and $5 \% \mathrm{CO}_{2}$ ). This was thereafter incubated for 4 hours at $37^{\circ} \mathrm{C}$, and the absorbances (OD) of the resultant solution were read at $490 \mathrm{~nm}$ using a BioTek microplate reader (Winooski, Vermont, USA).

Nitro-Blue Tetrazolium (NBT) Assay: On the other hand, Nitroblue tetrazolium (NBT) is a yellow water-soluble nitro-substituted aromatic tetrazolium compound that reacts with cellular superoxide ions to form formazan derivative that can be monitored spectrophotometrically. The cytoplasmic NADPH, which is produced by oxidation of glucose through the hexose monophosphate shunt, serves as an electron donor, therefore the oxidase system available in the cytoplasm helps transfer electrons from NADPH to NBT and reduce NBT into formazan. Thus, the NBT reaction indirectly reflects the ROS-generating activity in the cytoplasm of DU-145 cells. Briefly, DU-145 cells were seeded at $1 \times 10^{4}$ cells per well in 96- well microplates and allowed to attach for 24 hours at $37^{\circ} \mathrm{C}$ and $5 \% \mathrm{CO} 2$. Relevant plates were treated as discussed previously. NBT $(1 \mathrm{mg} / \mathrm{mL})$ in HBSS medium was added to the wells 48 hours after treatment, and incubated for 4 hours at $37^{\circ} \mathrm{C}$ in the dark. NBT formazan formed in each wells were then solubilized with $100 \mu \mathrm{l}$ of DMSO for 30 minutes. ROS production levels were quantified using an absorbance microplate reader at $490 \mathrm{~nm}$. The results were expressed as relative percentage of ROS, and then normalized in which the control was zeroed.

Acridine Orange/Ethidium Bromide Fluorescence Assay: The acridine orange (AcrO)/ethidium bromide (EtBr) fluorescence assay was used to differentiate between viable, apoptotic, and necrotic cells based on fluorescence emission characteristics of acridine orange and ethidium bromide. Acridine orange permeates both viable and nonviable cells, causing the nuclei to emit green fluorescence. Since absorption of ethidium bromide is based on the disruption of cell membrane integrity, ethidium bromide selectively stains the nuclei of dead (non-viable) cells to produce orange or red fluorescence. Cells that emit orange/brown colored 
fluorescence are indicative of apoptosis, while necrotic cells emit red fluorescence. Briefly, ethidium bromide $(25 \mu \mathrm{L})$ and acridine orange $(75 \mu \mathrm{L})$ were mixed to make a cocktail in which 3 $\mu \mathrm{L}$ of it was added to $25 \mu \mathrm{L}$ of the cell suspensions. Wet-mounts were prepared using $10 \mu \mathrm{L}$ of each cell suspension and analyzed under a fluorescent microscope with a bandpass filter. Apoptotic cell death was quantified by counting a total of 100 cells per 2 to 3 fields of view. For each relevant treatment regimen, fluorescence micro photographed pictures were taken directly from under the fluorescence microscope using a digital camera (Nikon: Coolpix VR \& ISO 2000, Japan).

Rhodamine 123/Ethidium Bromide Fluorescence Assay: The rhodamine 123 (Rh123)/ethidium bromide (EtBr) fluorescence assay was used to assess the mitochondrial membrane potential $(\Delta \Psi \mathrm{m})$ in treated cells and also used to differentiate between viable, apoptotic, and necrotic cells, as well as to determine the possible mechanism of apoptosis, based on mitochondrial transmembrane potential. Rh123 is a cationic fluorochrome, which utilizes the transmembrane potential of active mitochondria to diffuse into cells. The intact mitochondrial membranes of viable DU-145 cells allow for the absorption of the dye, resulting in the emission of bright green fluorescence. DU-145 cells, in which the integrity of the mitochondrial membrane has been impaired (non-viable cells), stain lightly with Rh123. Meanwhile, ethidium bromide selectively enters the disrupted membranes of dead cells and stains the nuclei to produce orange and red fluorescence. Cell samples were briefly washed three times in PBS and resuspended in a final volume of $20 \mu \mathrm{L} .2 \mu \mathrm{L}$ of the Rh123 stock solution was added to each cell suspension and was incubated at $37^{\circ} \mathrm{C}$ for 5 minutes. $20 \mu \mathrm{L}$ of EtBr stock solution was then added to each cell suspension and this was incubated at room temperature for 5 minutes. Finally, $10 \mu \mathrm{L}$ of each cell mixture was transferred onto a microscope slide covered with a coverslip and examined/analyzed under a fluorescent microscope with a band-pass filter. Green fluorescence is indicative of viable cells; orange/brown cells are apoptotic while necrotic cells emit red fluorescence. The percentage of apoptotic cell death was quantified from an average of 100 cells spread across two to three regions/views on each slide.

Statistical analysis: Experiments were performed in quadruplicate and repeated twice to confirm results. Significance of the differences in mean values was determined using Microsoft excel (v. 2013) and the Student's t-test. Statistical significance was defined as $P<0.05$.

\section{RESULTS:}

$\mathrm{MgCl}_{2}$ supplementation inhibited growth and proliferation of DU-145 prostate cancer cells: DU-145 human prostate cancer cell line was used to determine the chemosensitivity of hormone independent prostate cancer to $\mathrm{MgCl}_{2}$ supplementation in vitro using MTT and Resazurin (Alamar blue) reduction bioassays. $\mathrm{MgCl}_{2}$ was found to significantly inhibit cell growth and also decrease cell survival or viability [Figure $2 \& 3$ ]. The data indicated that DU-145 sensitivity to $\mathrm{MgCl}_{2}$ supplementation is dose-dependent. At lower concentrations, the DU-145 was significantly more sensitive $(P<0.05)$ at 90 and $100 \mu \mathrm{M}$ concentration with cell growth inhibition of $41 \%$ and $47 \%$ respectively from the MTT analysis, and $49 \%$ and $42 \%$ from the 
Alamar blue analysis. At higher concentrations, the greatest effect in this study was significantly greatest $(P<0.05)$ at $500 \mu \mathrm{M}$ concentration. From the MTT and Alamar blue cytotoxicity results, the $\mathrm{IC}_{50}$ was determined to be $460 \mu \mathrm{M}$ and $440 \mu \mathrm{M}$ respectively or within $440-460 \mu \mathrm{M}$ range when put together [Figure $2 \& 3$ ]. Figure $1 \mathrm{~A} \& \mathrm{~B}$ are showing the micrographs of the control and $\mathrm{MgCl}_{2}$ induced cytotoxic effect at $500 \mu \mathrm{M}$ respectively; characterized by massive population of apoptotic cells compared to the control.

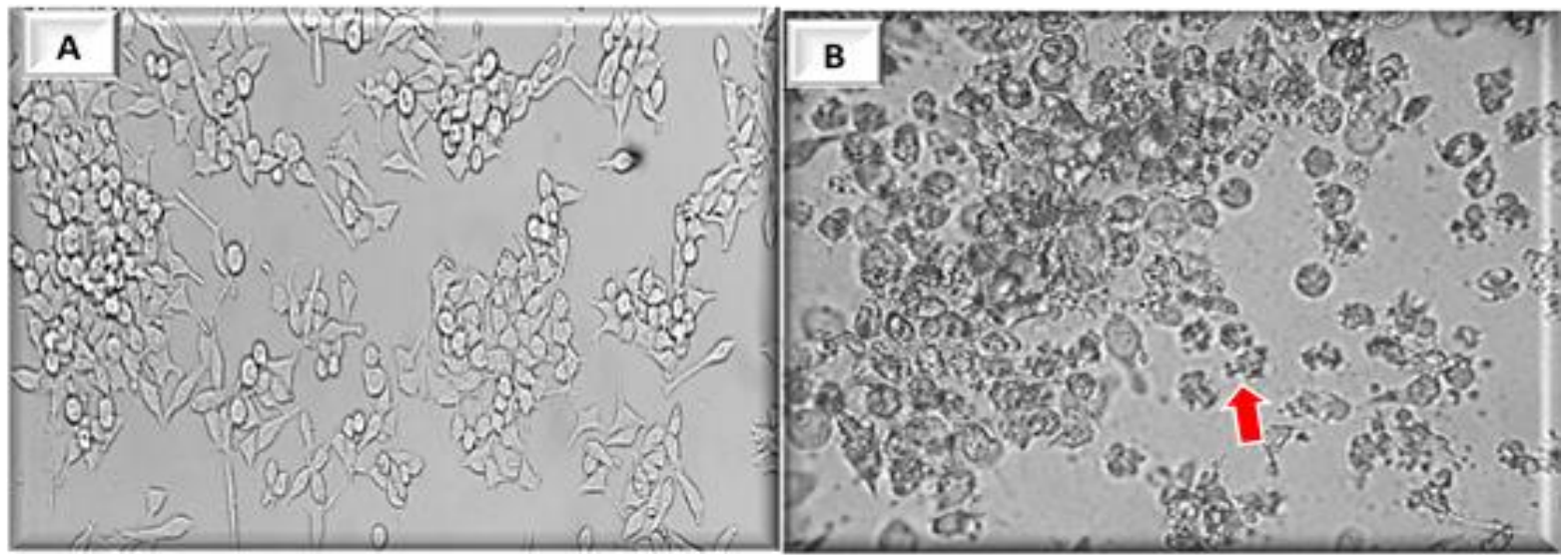

Figure 1 A \& B: Phase contrast micrographs (200X) of untreated and treated DU-145 cells. Figure 1A: Showing the micrographs of DU-145 cells on first day of culture in RPMI 1460 media. Figure 1B is showing the micrographs of untreated viable DU-145 cells at $85 \%$ confluence. Figure $1 \mathrm{~B}$ is showing micrograph of DU-145 cells following treatment with $\mathrm{MgCl}_{2}$ at $500 \mu \mathrm{M}$. The red arrow points to a cell that is sensitive (apoptotic) to the treatment. Other cells showing different hallmarks of apoptosis were observed. This micrograph was taken 48 hours post-treatment.

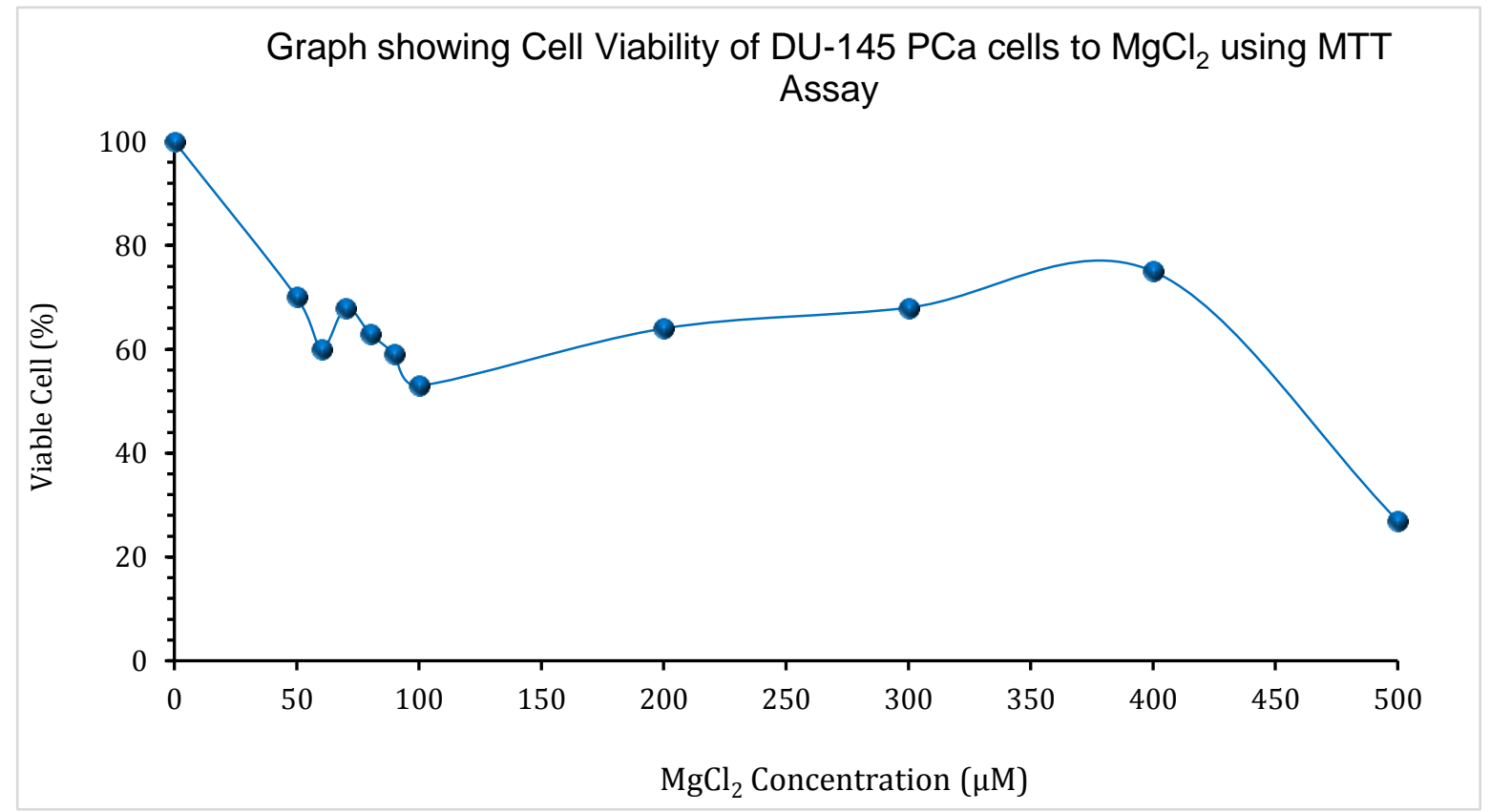

Figure 2: Graph showing the dose-effect curve of $\mathrm{MgCl}_{2}$-induced cytotoxicity in DU-145 PCa cells via MTT assay. There was a dose-dependent decrease $(P<0.05)$ in cell viability in treated DU-145 cells with graded concentrations from 50 to $500 \mu \mathrm{M}$ of $\mathrm{MgCl}_{2}$ after $48 \mathrm{hrs}$. Data points represent the mean values \pm SEM of two independent experiments performed in quadruplicate $(P<0.05)$. 
Graph showing Cell Viability of DU-145 PCa Cells to $\mathrm{MgCl}_{2}$ using Alamar Blue Assay

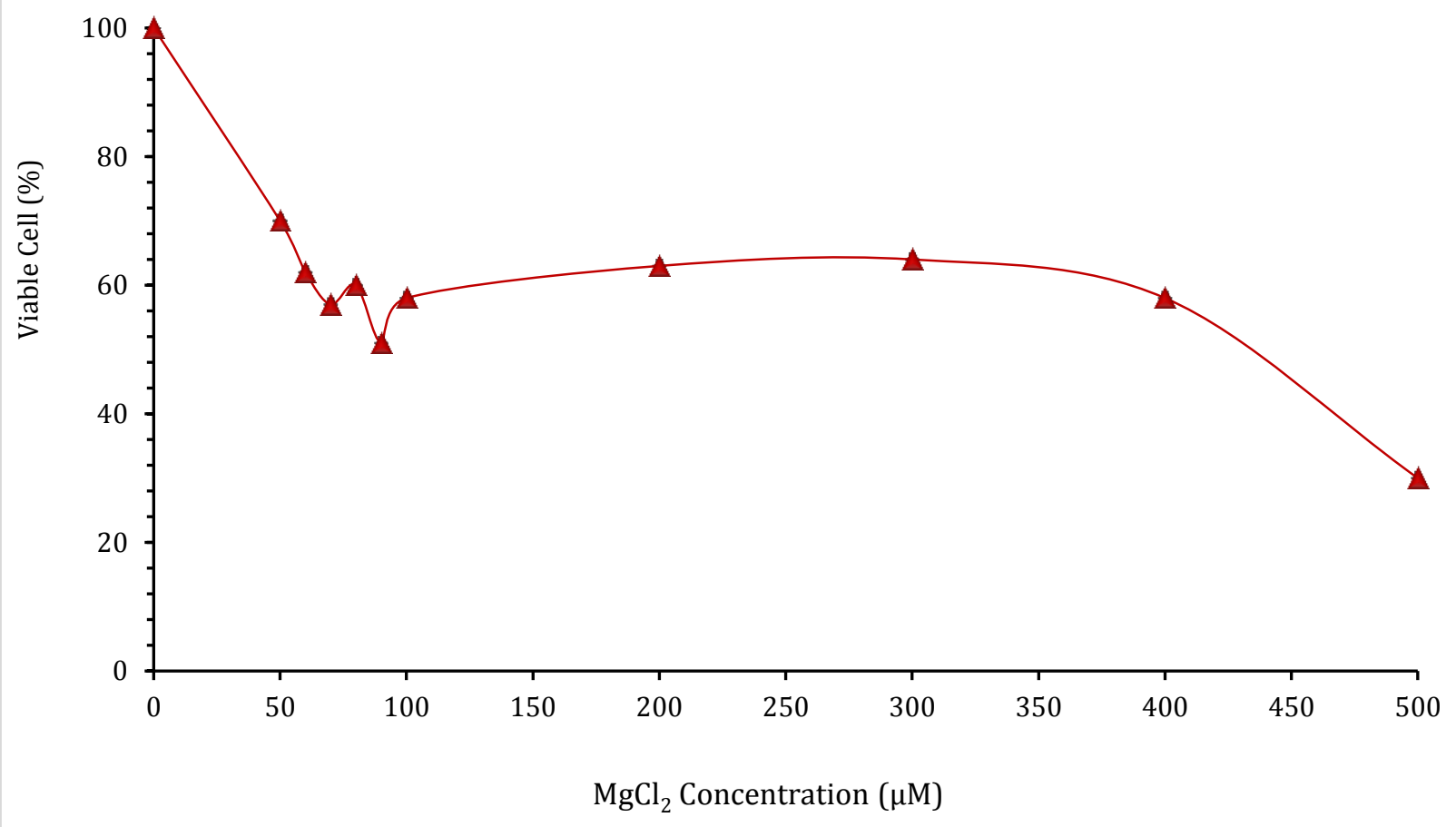

Figure 3: Graph showing the dose-effect curve of $\mathrm{MgCl}_{2}$-induced cytotoxicity in DU-145 PCa cells via Resazurin (Alamar Blue) Reduction Assay. There was a dose-dependent decrease $(P<0.05)$ in cell survival in treated DU-145 cells with graded concentrations from 50 to $500 \mu \mathrm{M}$ of $\mathrm{MgCl}_{2}$ after $48 \mathrm{hrs}$. Data points represent the mean values \pm SEM of two independent experiments performed in quadruplicate $(P<0.05)$.

$\mathrm{MgCl}_{2}$ supplementation induced a compromise in the mitochondrial membrane potential in DU-145 human prostate cancer cells: In order to determine the effect of different doses $(0,50,100,500 \mu \mathrm{M})$ of $\mathrm{MgCl}_{2}$ supplementation on the mitochondrial membrane integrity, Rhodamine 123/ Ethidium bromide fluorescent stain was used. This also gives us an assessment of the type of cell death and the mechanism by which apoptosis was programmed. The Rh123/EtBr fluorescent revealed that about $97 \%$ of the cells in the control $(0 \mu \mathrm{M})$ stained green, which demonstrate an intact mitochondrial $3 \%$ undergoing stress induced apoptosis. Following 48 hours incubation of DU-145 treated with $\mathrm{MgCl}_{2}$ at doses of 50, 100 and $500 \mu \mathrm{M}$, we observed a significant dose-dependent increase $(P<0.05)$ in apoptotic cells (27\%, $48 \%$ and $54 \%$ respectively) with compromised mitochondria and reduced transmembrane potential [Figure 4]. They visibly stained orange-brown. This probably suggests that $\mathrm{MgCl}_{2}$ supplementation utilize the intrinsic-mitochondrial apoptotic pathway and the activation of caspase proteases for its chemopreventive effects in hormone independent prostate cancer. 


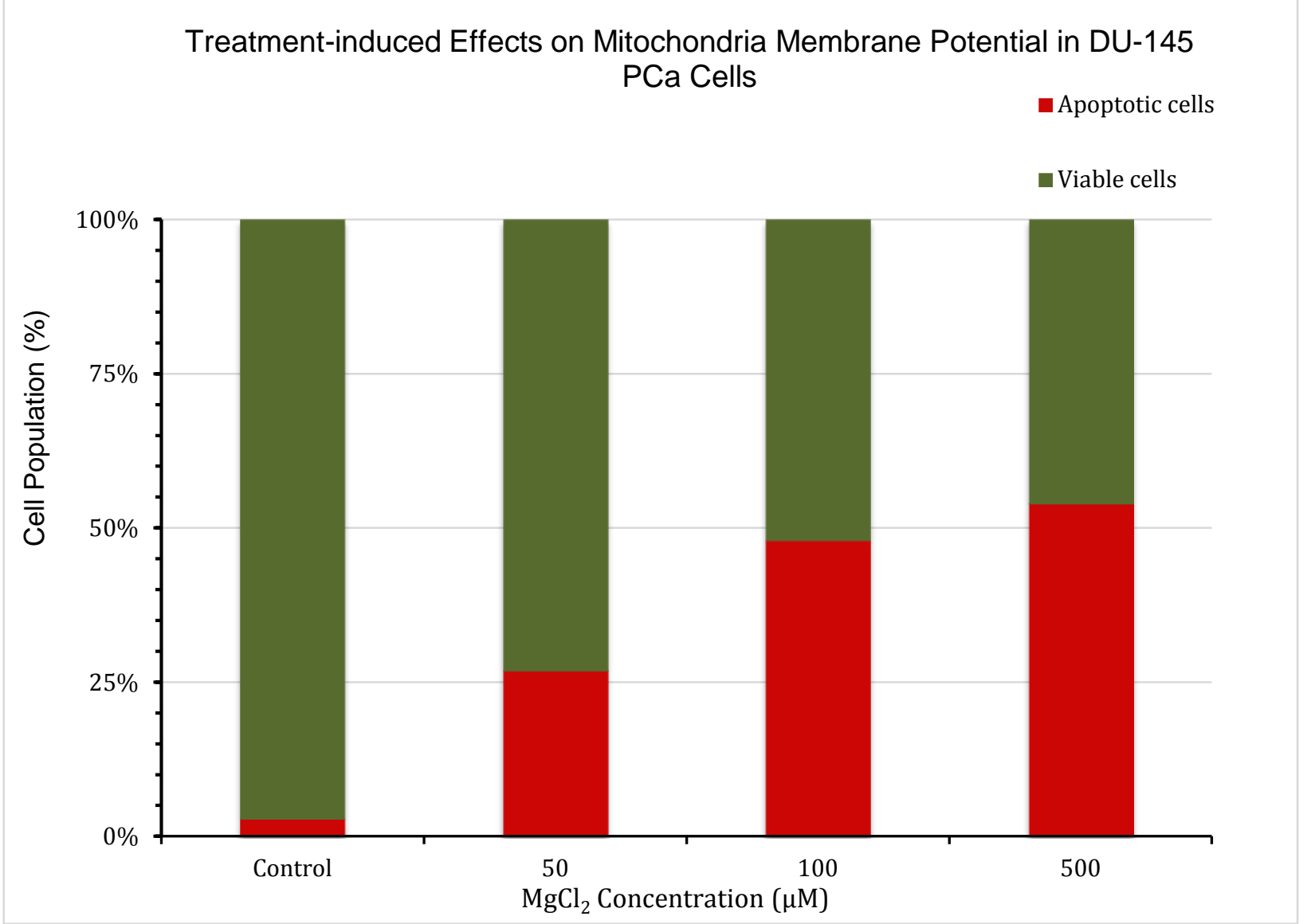

Figure 4: Bar-charts showing $\mathrm{MgCl}_{2}$-induced effects on the mitochondrial membrane potential ( $\left.\Delta \psi \mathrm{m}\right)$ of DU-145 PCa cells via Rh123/ EtBr Fluorescence Assay. There was a significant dose-dependent increase $(P<0.05)$ in compromise of the $\Delta \psi \mathrm{m}$. Apoptosis appears to be the major mode of cell death. At the highest concentration $(500 \mu \mathrm{M})$ more apoptotic cells were observed with reduced mitochondrial transmembrane potential. Data points represent the mean values \pm SEM of two independent experiments performed in quadruplicate $(P<0.05)$.

\section{$\mathrm{MgCl}_{2}$ supplementation induced apoptosis in DU-145 human prostate cancer cells}

Extensive cell deaths if the treatment induced cell death occurred through cytotoxic necrosis and / or apoptosis, cells were fluorescently stained with $\mathrm{AcrO} / \mathrm{EtBr}$ after $48 \mathrm{hrs}$. of incubation, in which live cells pick up the acridine orange dye and stain green, while the damaged cells pick up the ethidium bromide dye and stain orange-brown, depending on the stage of apoptosis. This can also give us a qualitative state of apoptotic cell death in different cells exposed to different levels of treatment, especially at $0,50,100$, and $500 \mu \mathrm{M}$ concentrations of $\mathrm{MgCl}_{2}$. The micrographs qualitatively show that cell death was mostly due to apoptosis in a dose-dependent manner [Figure $7 \mathrm{~A}$ - F]. More apoptotic cell death (orangebrown stained cells) was observed in micrographs containing DU-145 exposed to $\mathrm{MgCl}_{2}$ at $500 \mu \mathrm{M}$ compared to at $50 \mu \mathrm{M}$. 

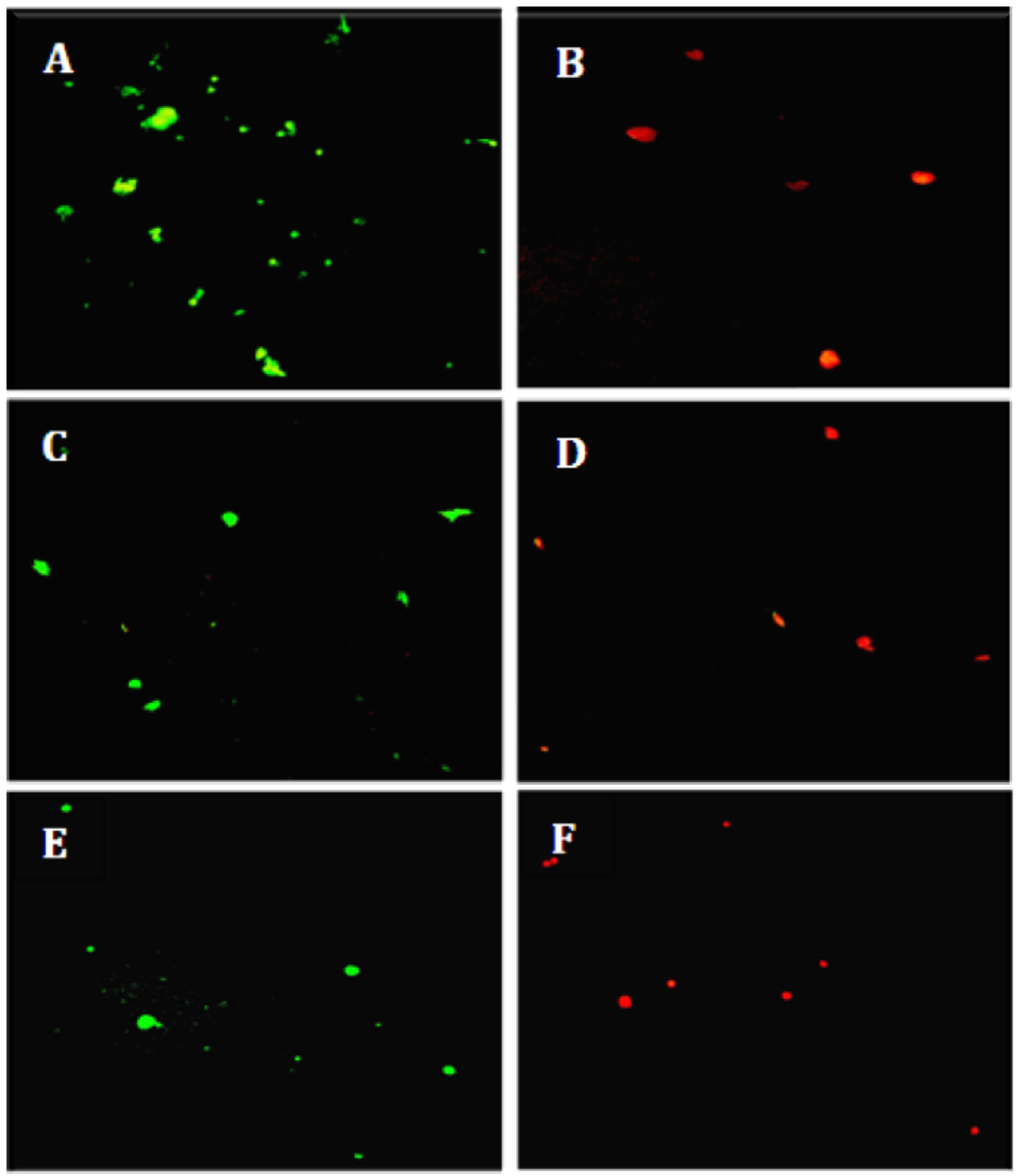

Figure 7 A to F: Micrographs (200X) of Acridine Orange / Ethidium Bromide fluorescently stained DU-145 cells following treatment with $\mathrm{MgCl}_{2}$ at $50 \mu \mathrm{M}, 100 \mu \mathrm{M}$, and $500 \mu \mathrm{M}$. Showing qualitatively apoptosis as the main form of induced cell death in a dose-dependent mode. Figures 7A, 7C and 7E are showing the micrographs of AcrO fluorescently stained DU-145 cells at $50 \mu \mathrm{M}, 100 \mu \mathrm{M}$, and $500 \mu \mathrm{M}$ respectively. Figures 7B, 7D, and 7F are showing the micrographs of EtBr fluorescently stained DU-145 cells at $50 \mu \mathrm{M}, 100 \mu \mathrm{M}$, and $500 \mu \mathrm{M}$ correspondingly. Acridine orange stained live cells green and Ethidium bromide stained apoptotic cells orange-red depending on the stage of apoptosis. This micrograph was taken 48 hours post-treatment. 
$\mathrm{MgCl}_{2}$ supplementation increased $\mathrm{ROS}$ generation in DU-145 human prostate cancer cells

Since we already elucidated the effects of $\mathrm{MgCl}_{2}$ supplementation in DU-145, our next goal was to assess the role of $\mathrm{MgCl}_{2}$ on intracellular ROS generation. The NBT assay was used to assess the change in intracellular ROS levels following exposure of DU-145 cells to different concentrations of $\mathrm{MgCl}_{2}$ at 50,60,70,80,90,100,200,300,400,500 $\mu \mathrm{M}$ compared to the control $(0 \mu \mathrm{M})$. The data was zeroed to show the increase or decrease in ROS levels relative to the control or untreated group. NBT assay ROS data also revealed a dose dependent biphasic response $(P<0.05)$ in intracellular levels of ROS in DU-145 cells. There was a drop $(P<0.05)$ in ROS levels in all treated groups except at $100 \mu \mathrm{M}$, where ROS levels were found to be higher than the control [Figure 5]. This suggests that at $100 \mu \mathrm{M}$ supplementation, there was a shift from its antioxidant activity to pro-oxidant activity, but further increase in the dose of $\mathrm{MgCl}_{2}$ returns the ROS levels to below the control again. Put together, there is the possibility that $\mathrm{MgCl}_{2}$ inhibit DU-145 cell growth via free radical scavenging in which the ROS levels are dropped below the normal required for the normal proliferation of the cancer cell. At $100 \mu \mathrm{M}$, a significant rise $(P<0.05)$ in ROS generation was observed. Either way, the cancer cell viability rate was still drastically reduced [Figure 6].

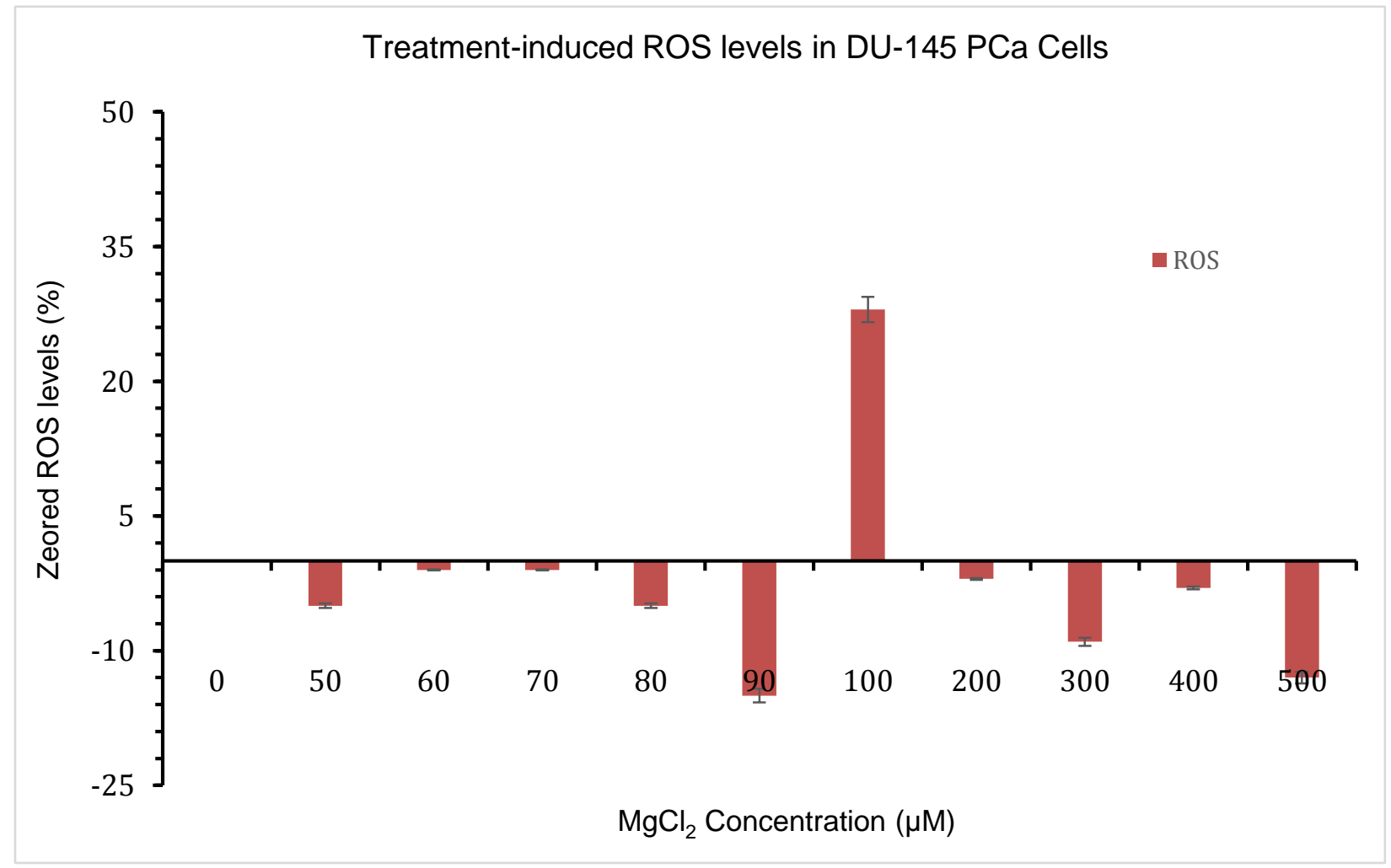

Figure 5: Bar-chart showing the $\mathrm{MgCl}$-induced ROS level in DU-145 PCa cell lines via Nitro-blue tetrazolium (NBT) assay. There was a biphasic dose-dependent response $(P<0.05)$ in intracellular levels of ROS in DU-145 PCa cells with graded concentrations from 50 to $500 \mu \mathrm{M}$. Significant decrease in ROS levels below the control $(0 \mu \mathrm{M})$ were observed except at $100 \mu \mathrm{M}$ concentration in treated DU-145 cells after $48 \mathrm{hrs}$, where the ROS level was significantly higher $(P<0.05)$ than the control $(0 \mu \mathrm{M})$. Data points represent the mean values \pm SEM of two independent experiments performed in quadruplicate $(P<0.05)$. 
Correlation between $\mathrm{MgCl}_{2}$ Cell Viability vs ROS in DU-145 PCa Cells

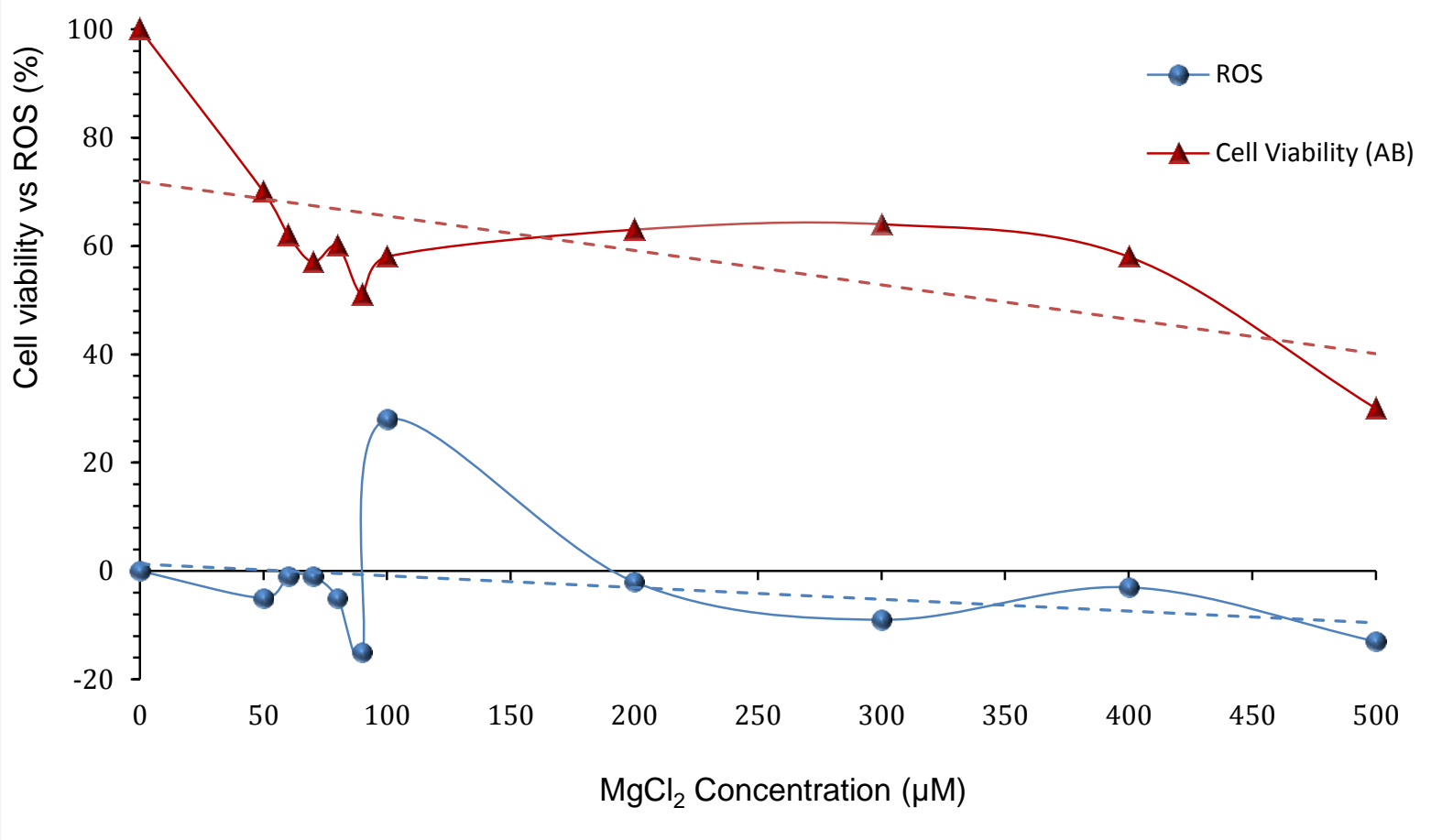

Figure 6: Graphs showing the correlation between the $\mathrm{MgCl}_{2}$-induced Cell viability vs ROS levels. Both cell viability and ROS generation showed a dose-dependent response in DU-145 prostate cancer cells treated with different concentrations of $\mathrm{MgCl}_{2}$. Even though at $100 \mu \mathrm{M}$, a significant increase $(P<$ $0.05)$ in ROS generation was perceived, cell viability was positively correlated. Data points represent the mean values \pm SEM of two independent experiments performed in quadruplicate $(P<0.05)$.

\section{DISCUSSION:}

The role of magnesium in cancer prevention and progression is still emerging and at present tainted with ambiguity from reports in the literature. This is due to multiple role of magnesium in the body, and it's overly distribution in different tissues in the body [13]. The status of magnesium has been shown to be biphasic, in which changes in cellular magnesium can either stimulate or inhibit cancer growth and progression. In other words, this means that it has both anticancer effect and also carcinogenic effect. However, we believe that this variation in activity may be related to activation of cellular transduction pathways as a result of disparity in the concentration of magnesium in extracellular and intracellular compartments. Many studies have focused on the extracellular serum levels of magnesium as prognostic and diagnostic tools for hypomagnesemia or hypomagnesemia [5]; hence neglecting the intracellular regulation of magnesium in target tissues.

This inequality in intracellular and extracellular levels of magnesium becomes challenging when diagnosing magnesium deficiency-related disorders, and further supports the fact that serum magnesium levels may not precisely reflect the overall magnesium status of a patient. Moreover, tumor cells have been demonstrated to function independently of the extracellular status of magnesium [14]. 
Drugs that have the ability to scavenge for magnesium, such as Cisplatin have been shown to lower the intracellular levels of magnesium in the body, hence causing hypomagnesemia [15 \& 16]. Approximately $50 \%$ of the testicular cancer patients treated with Cisplatin were reported to have low levels of magnesium due to defect that may be related to magnesium absorption by the cells. This suggests that disproportionality in the intracellular levels of magnesium in cancer cells compared to normal cells in the body, as well as the level that can be found in the blood are factors that should be considered, when making a prognostic and diagnostic inferences, especially considering the role magnesium may be playing in cancer progression and inhibition.

In addition, hypomagnesaemia has also been associated with the incidence and decreased survival rate in chronic pathologies such as diabetes, cancer, coronary heart disease and hypertension [9]. In a histopathological study of a carcinomatous prostate gland, the prostate cancer cells failed to show staining reactions for magnesium despite appearing morphologically differentiated. Unlike in the cancer cells, the prostate epithelial cells showed a strong positive staining of the prostate acini [17].

The scope of this study was to investigate the role of magnesium supplementation in the prostate cancer development, and also assess the dose-dependent effects of magnesium chloride in DU-145 - a hormone independent prostate cancer cell line. The cancer cells were subjected to varied concentrations of magnesium chloride and the level of dose-response was assessed using batteries of cell proliferation and inhibition assays. In this study, DU-145 PCa cells were found to be responsive to $\mathrm{MgCl}_{2}$ levels dose-dependently. A significant increase $(P<0.05)$ in cell growth inhibition was observed with an increase in concentration of $\mathrm{MgCl}_{2}$. This is in congruity with prior studies, in which magnesium supplementation was found to show anti-carcinogenic effect on 3-MC-induced fibrosarcoma [13].

The major mode of cell death was found to be apoptosis, and also found to increase with an increase in the concentration of $\mathrm{MgCl}_{2}$ supplementation. Apoptosis has been used for many years by researchers as a dosimeter for programmed cell death, which is controlled by the disparity in the expression of pro-death and anti-death molecules in the body [18]. This means that the presence of damaged or mutated cell in a tissue create a pathway geared towards the elimination of such abnormal cell. Magnesium has also been demonstrated to be involved in membrane transport and cellular repair [19].

In this study, DU-145 cells treated with $\mathrm{MgCl}_{2}$ were found to show more sensitivity to magnesium levels, especially at a higher concentration of $\mathrm{MgCl}_{2}(100-500 \mu \mathrm{M})$. We also observed that high concentrations of $\mathrm{MgCl}_{2}$ caused a relative decrease in the mitochondrial membrane potential visualized from the fluorescence imaging and staining with $\mathrm{Rh} 123 / \mathrm{EtBr}$. This is in concert with prior studies, in which magnesium was shown to act as a second intracellular messenger involved in the regulation of apoptosis downstream. In addition, an increase in magnesium levels was correlated with a rise in cytochrome $\mathrm{C}$ release from the mitochondria, which is known as a driver for the post-mitochondrial, caspase-mediated apoptotic events in cells [20]. Another study conducted on drinking water containing magnesium in Taiwan show that a protective effect from the risk of prostate cancer was apparent in groups with the highest levels of magnesium in their body [21].

Moreover, the normal range for serum magnesium concentration in humans is between 750 and $950 \mu \mathrm{M} / \mathrm{L}$ [22]. In this study, our $\mathrm{IC}_{50}$ was within $440-460 \mu \mathrm{M}$ range, suggesting that the 
presence of magnesium at high levels might be linked with decrease in tumor proliferation or growth; and hence may be of clinical significance in increasing the survival rate of prostate cancer patients.

Majority of the cell death recorded in this study were due to apoptosis, reflected by cells showing different hallmarks of apoptosis. Some of the observed hallmarks include; cell shrinkage, nuclear condensation, membrane blebbing, and formation of apoptotic bodies similar to what was previously reported [23]. In a prior study, an increase in the level of magnesium compounds to $1 \mathrm{mM}$ concentration, was found to increase the apoptotic fragmentation of DNA in cells after 15 hours of culture and reported to be more pronounced at 30 hours post-treatment compared to when the cells were not exposed to magnesium compounds at all [24]. Another study reported Fas-initiated apoptosis as a result of Mg mobilization in B cells [25]. They also noticed that the increase in Magnesium mobilization correspond with an increase in DNA fragmentation and externalization of phosphatidylserine, in which the cytosolic increase in levels of magnesium was found to be higher in cells undergoing apoptosis [12]. Thus, emphasizing the role of magnesium as a phase II intracellular messenger involved in downstream events in apoptosis.

Meanwhile, in another study, co-administration of magnesium with antioxidants such as vitamin $\mathrm{C}$ and vitamin $\mathrm{E}$ inhibited the apoptotic pathway in more than $50 \%$ cases, indicating that magnesium may be involved in the cellular redox reactions and extracellular signaling for apoptosis [26]. This further buttress our finding in which dose-dependent biphasic ROS generation responses to magnesium chloride supplementation-induced cytotoxicity was observed. The results presented herein indicate that magnesium chloride supplementation has dose-dependent modulatory effects - anti-proliferative and apoptotic - on DU-145 prostate cancer cells, thus emphasizing its potential as a chemopreventive mineral for prostate cancer.

\section{CONCLUSION:}

Our finding suggests that magnesium chloride supplementation or a diet rich in magnesium may be potentially chemopreventive for prostate cancer. This justifies further studies into its mechanism of action in DU-145 and in other prostate cancer cell types.

Abbreviations: PCa: Prostate cancer; $\mathrm{MgCl}_{2}$ : Magnesium chloride; AcrO/EtBr: Acridine orange/Ethidium bromide; ROS: Reactive oxygen species; Rh123/EtBr: Rhodamine123/ Ethidium bromide; $\Delta \psi \mathrm{m}$ : Mitochondrial membrane potential; NBT: Nitroblue tetrazolium assay; MTT: 3-(4, 5-dimethyl thiazolyl-2)-2, 5-diphenyltetrazolium bromide.

Competing Interests: All authors have declared that there is no conflicting interest.

Authors' Contributions: All authors contributed equally to this study.

\section{REFERENCES:}

1. SEER. Cancer statistics factsheets: Prostate Cancer. National Cancer Institute. Bethesda, MD, http://seer.cancer.gov/statfacts/html/prost.html. 
2. American Cancer Society. Cancer facts and figures. Atlanta, USA 2015. www.cancer.org/acs/groups/content.

3. Sakr WA, Grignon DJ, Haas GP, et al. Age and racial distribution of prostatic intraepithelial neoplasia. European Urology 1996; 30 (2): 138-44.

4. Kumi-Diaka J, Merchant K, Haces A, et al. Genistein-selenium combination induces growth arrest in prostate cancer cells." Journal of Medicinal Food 2010; 13 (4): 842-850.

5. Guerrera MP, Volpe SL, and Mao JJ. Therapeutic uses of magnesium. American Family Physician 2009; 80:1-6.

6. Durlach J, Bara M. Le Magnésium en biologie et en médecine. Cachan (France): Ed. Med. Int., 2000; 443.

7. Rayssiguier Y, Durlach J, Guex E, et al. Magnesium and aging I. Experimental data: importance of oxidative damage. Magnesium Research 1993; 6: 369-378.

8. Cappadone C, Merolle L. et al. Intracellular magnesium content decreases during mitochondria-mediated apoptosis induced by a new indole-derivative in human colon cancer cells. Magnesium Research 2012; 25(3): 104-11.

9. Swaminathan R. Magnesium metabolism and its disorders. Clinical Biochemical Revision 2003; 24: 47-66.

10. Lichton I J. Dietary intake levels and requirements of $\mathrm{Mg}$ and $\mathrm{Ca}$ for different segments of the U.S. population. Magnesium 1989; 8(3-4): 117-23.

11. NRC (National Research Council). Recommended Dietary Allowances. National Academy Press 10th Edition 1989: 187-184.

12. Tam M, Gomez M, \& Marcos A. Possible roles of magnesium on the immune system. European Journal of Clinical Nutrition 2003; 57:1193-1197.

13. Patiroğlu T, Şahin G, Kontaş O, et al. Protective effect of magnesium supplementation on experimental 3-methyl cholantrene-induced fibrosarcoma and changes in tissue magnesium distribution during carcinogenesis in rats. Biological Trace Element Research 1996; 56: 179-185.

14. Wolf FI, Trapani V and Cittadini A. Magnesium and the control of cell proliferation looking or a needle in a haystack. Magnesium Research 2008; 21(2): 83-91.

15. Willox JC, McAllister EJ, Sangster G, and Kaye SB. Effects of magnesium supplementation in testicular cancer patients receiving cisplatin: a randomized trial. British Journal of Cancer 1986; 54(1): 19-23.

16. Lajer H, Frøkiær M \& Daugaard G. Magnesium depletion enhances cisplatin-induced nephrotoxicity. Cancer Chemotherapeutic Pharmacology 2005; 56: 535-542.

17. Gyërkey F, Min KW, Huff JA \& Gyërkey P. Zinc and magnesium in human prostate gland: Normal, Hyperplastic, and Neoplastic. Cancer Research 1967; 27: 1348-1353.

18. Oseni SO, Kumi-Diaka J, Branly R et al. Pyroelectrically generated very low dose ionizing radiation potentiates the effects of genistein isoflavone in human prostate cancer cells. Journal of Cancer Prevention \& Current Research 2014; 1(2):14.

19. Lajer H and Daugaard G. Cisplatin and hypomagnesemia. Cancer Treatment Revision 1999; 25(1): 47-58.

20. Widlak P \& Garrard WT. Ionic and cofactor requirements for the activity of the apoptotic endonuclease DFF40/CAD. Molecular Cellular Biochemistry 2001; 218(1): 125-130. 
21. Yang CY, Chiu HF, Tsai SS, et al. Calcium and Magnesium in drinking water and risk of death from prostate cancer. Journal of Toxicology and Environmental Health, Part A: Current Issues 2000; 60:17-26.

22. Institute of Medicine (IOM). Food and Nutrition Board. Dietary Reference Intakes: Calcium, Phosphorus, Magnesium, Vitamin D and Fluoride. Washington, DC: National Academy Press, 1997.

23. Hu W and Kavanagh JJ. Anticancer therapy targeting the apoptotic pathway. The Lancet Oncology 2003; 4(12): 721-729.

24. Black S, Yu H, Lee J, Sachchithananthan M and Medcalf R. Physiologic concentrations of magnesium and placental apoptosis: prevention by antioxidants. Obstetric Gynecology 2001; 98, 319-322.

25. Chien MM, Zahradka KE, Newell MK \& Freed JH. Fas-induced B cell apoptosis requires an increase in free cytosolic magnesium as an early event. The Journal of Biological Chemistry 1999; 274(11): 7059-7066.

26. Khalid R. Studies on free radicals, antioxidants, and co-factors. Clinical Interventions in Aging 2007; 2(2): 219-236. 